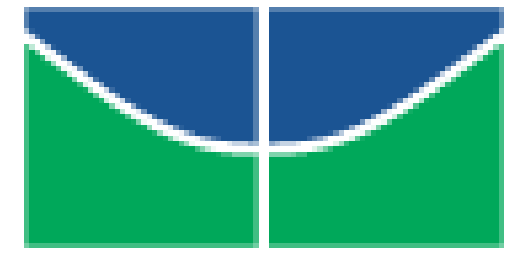

UNIVERSIDADE DE BRASÍLIA

Faculdade de Educação UAB/UnB/MEC/SECAD

Curso de Especialização em Educação na Diversidade e

Cidadania, com Ênfase em EJA

lêda Maria Ferreira dos Santos

\title{
Laboratório de Leitura
}

BRASÍLIA, DF

JULHO/2010 


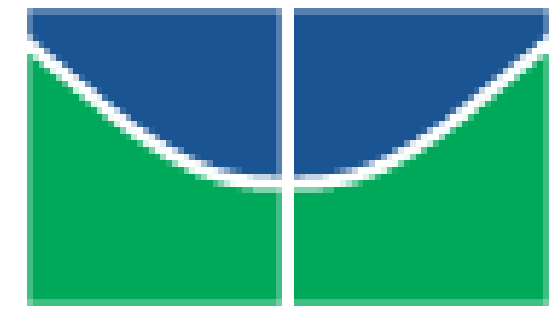

UNIVERSIDADE DE BRASÍLIA

Faculdade de Educação UAB/UnB/MEC/SECAD

Curso de Especialização em Educação na Diversidade e Cidadania, com Ênfase em EJA

\section{Laboratório de Leitura}

lêda Maria Ferreira dos Santos

Professora orientadora: Ruth Gonçalves Faria Lopes

Tutora orientadora: Professora: Cléssia Mara Santos

Projeto de Intervenção Local

Brasília, DF

Julho /2010 


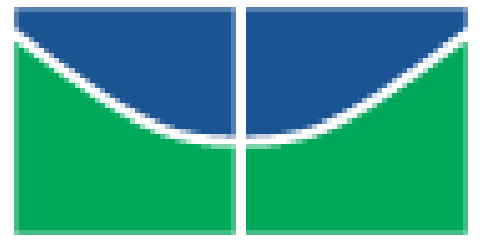

UNIVERSIDADE DE BRASÍLIA

Faculdade de Educação UAB/UnB/MEC/SECAD

Curso de Especialização em Educação na Diversidade e

Cidadania, com Ênfase em EJA

IÊDA MARIA FERREIRA DOS SANTOS

Trabalho de conclusão do curso de Especialização em Educação na Diversidade e cidadania, com ênfase em EJA, como parte dos requisitos necessários para a obtenção do grau de Especialista na Educação de Jovens e Adultos.

Ruth Gonçalves Faria Lopes

Professor Orientador

Cléssia Mara Santos

Tutor Orientador

Letícia de L. Curado Teles

Avaliador Externo

BRASÍLIA, DF 
Julho/2010 
Dedico este trabalho primeiramente a Deus, pois sem "Ele", nada seria possível.

À minha família, pelo incentivo e apoio. 


\section{AGRADECIMENTOS}

Aos Professores, principalmente à Professora Cléssia Mara Santos, pela dedicação e empenho que demonstraram no decorrer de suas atividades para com o grupo. 
"Tudo o que um sonho precisa para ser realizado é alguém que acredite que ele possa ser realizado".

(Roberto Shinyashiki) 


\section{RESUMO}

O projeto visa incentivar o hábito da leitura nos alunos do Ensino Fundamental - modalidade EJA. Constitui-se de uma alternativa lúdica de consolidação do interesse pela leitura. O objetivo principal é estimular a criatividade, o espírito inventivo e a curiosidade dos estudantes com a intenção de contribuir para formar uma nova geração de leitores, mais crítica. Destaca-se alguns aspectos históricos que posicionam o progresso e o avanço da leitura, discute-se a importância da família e da escola neste processo. Enfatizam-se os caminhos e reflexões sobre o despertar do gosto pela leitura. O projeto vai devolver a auto-estima ao promover a integração social, desenvolver um olhar crítico aos alunos do CEF Centro de Ensino Fundamental 2 do Riacho Fundo I - modalidade EJA- Ensino de Jovens e Adultos.

Palavras-chave: Leitura; Aprendizagem; Conscientização; Letramento. 


\section{SUMÁRIO}

1 - DADOS DE IDENTIFICAÇÃO DO(S) PROPONENTE (S) ........................................

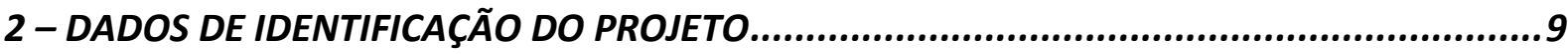

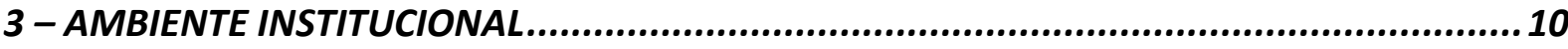

4 - JUSTIFICATIVA E CARACTERIZAÇÃO DO PROBLEMA .......................................... 10

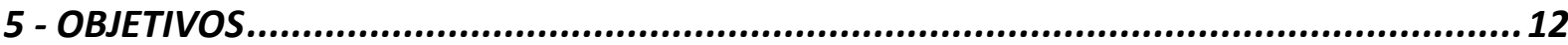

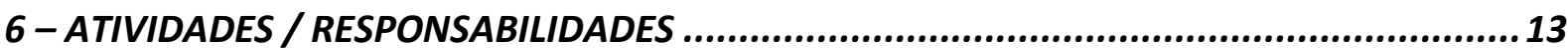

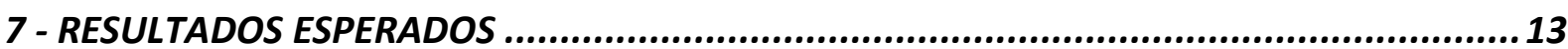

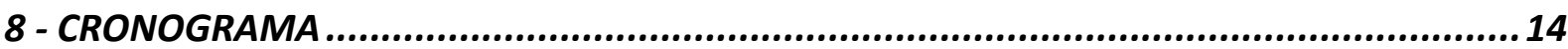

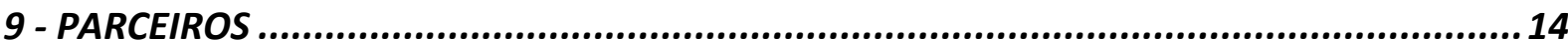

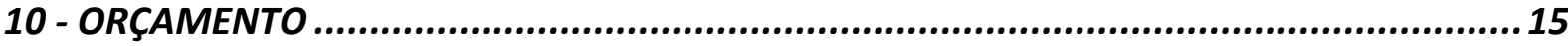

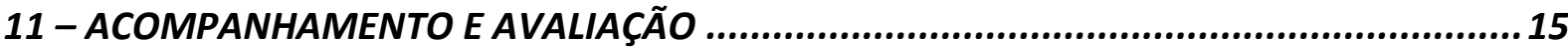

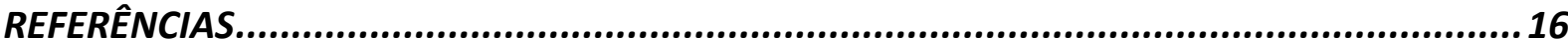


PIL - PROJETO DE INTERVENÇÃO LOCAL

\section{1 - DADOS DE IDENTIFICAÇÃO DO PROPONENTE}

1.1- Nome: leda Maria F. dos Santos.

1.2- Turma: $G$

1.3- Informações para contato:

1.4- Telefone: $92110075 \quad$ E-mail: iedamf@bol.com.br

\section{2 - DADOS DE IDENTIFICAÇÃO DO PROJETO}

\section{1- Título: Laboratório de Leitura.}

2.2- Área de abrangência:

( ) Nacional ( ) Regional ( ) Estadual ( ) Municipal ( ) Distrital (X ) Local

\section{3-Instituição:}

Nome: Centro de Ensino Fundamental 02 do Riacho Fundo I

Endereço: QS 08 - Área Especial

Riacho Fundo I - Tel.: 33995978

Instância institucional de decisão:

Escola: Núcleo de Supervisores pedagógicos

\section{4 -Caracterização do Público Alvo}

O Centro de Ensino Fundamental 2 do Riacho Fundo I atende ao $2^{\circ}$ e $3^{\circ}$ segmentos de EJA- Ensino de Jovens e Adultos, noturno. O $2^{\circ}$ segmento é constituído por sua maioria adulta, homens e mulheres que buscam pela informação, pelo conhecimento e garantir um espaço na sociedade para a interação sistemática com a informação veiculada cotidianamente, o que contribui para a formação de alunos críticos na construção e reconstrução de novos conhecimentos. Percebe-se uma realidade quanto aos alunos que não tem o hábito da leitura. 


\section{5- Período de Execução}

Agosto a Dezembro de 2010.

\section{3 - AMBIENTE INSTITUCIONAL}

A escola na qual atuo, fica situada no Centro de Ensino Fundamental 2 do Riacho Fundo I, que está localizado na Região Administrativa XVII, sito à: QN 07 AE 12 RIACHO FUNDO I, telefone: 3901-5978.

A instituição atende cerca de 1.300 alunos nos seguintes níveis: Série Finais do Ensino Fundamental no turno matutino e Vespertino; e EJA - Educação de Jovens e Adultos $2^{\circ}$ e $3^{\circ}$ Segmentos, no noturno.

Temos como membros da direção, a diretora Claudia Moraes, a vice-diretora Jane Karla.

O ambiente escolar propicia boas condições de trabalho para a formação de leitores, biblioteca com acervo atualizado, profissionais da área em seus devidos espaços de trabalho, seja professor, seja bibliotecário (incentivando os discentes para o hábito e o gosto pela leitura com a metodologia através de leituras individuais e coletivas).

A escola promove um espaço interativo, participativo e tenta extrair dos discentes o conhecimento tácito que estes têm para enriquecimento da discussão, uma vez que cabe ao educador ser estimulador de leituras, não podendo ficar omisso diante dos acontecimentos que ocorrem com a comunidade que a freqüenta e com os futuros usuários.

\section{4 - JUSTIFICATIVA E CARACTERIZAÇÃO DO PROBLEMA}

Na EJA observa-se que há uma resistência grande por parte dos alunos em interpretar textos. Infelizmente nossos alunos (quase todos, no país) não têm o hábito de ler. O prejuízo é inestimável, sabemos todos. Faz-se necessário conscientizar nossos alunos para a necessidade de intensificação de ações de incentivo à leitura, dos seus benefícios. Percebese um desestímulo em nossa escola por parte dos alunos da EJA-Ensino de Jovens e Adultos mais de $80 \%$ dos alunos não lêem jornais nem revistas e o restante, $20 \%$ varia muito no grau de compreensão de texto. Os alunos precisam compreender a importância de se manterem atualizados, pois ler é essencial. Através da leitura, testamos os nossos próprios valores e experiências com as dos outros. No final de cada livro ficamos enriquecidos com novas 
experiências, novas idéias, novas pessoas. Eventualmente, ficaremos a conhecer melhor o mundo e um pouco melhor de nós próprios.

Nada desenvolve mais a capacidade verbal que a leitura de livros. Na escola aprendemos gramática e vocabulários. Contudo, essa aprendizagem nada é comparada com o que se pode absorver de forma natural e sem custo através da leitura regular de livros.

Um aspecto fundamental para que o projeto possibilite uma efetiva aprendizagem deve trazer os sujeitos bibliotecário e professores para este desafio para orientar, estimular o pensar, o refletir, o participar e o agir dos alunos. E em nossa escola observam-se dificuldades em realizar este projeto juntamente com os colegas, uma vez que acreditam que este papel deva ser feito somente pelos professores de Língua Portuguesa.

A leitura é uma atividade que se realiza individualmente, mas que se insere num contexto social, envolvendo disposições atitudes e capacidades que vão desde a decodificação do sistema de escrita até a compreensão e a produção de sentido para o texto lido.

Sabe-se que um dos principais problemas na educação da atualidade é a dificuldade que os educandos têm de ler e produzir textos. Essa é uma reclamação constante não só pelos professores da disciplina Língua Portuguesa, mas de toda a categoria docente.

A leitura proficiente tem infinitas possibilidades. Ela começa pelos olhos, mas vai além deles, pois necessita de um elemento fundamental para a compreensão, que é o conjunto de conhecimentos prévios relacionados ao assunto do texto lido. Por isso, a capacidade do ser humano de compreender os textos depende da relação entre o cérebro e os olhos.

Também faz parte desse processo de compreensão, o tipo de linguagem utilizada no texto, que pode facilitar ou dificultar a leitura. Se o leitor não domina o tipo de linguagem do texto, dificilmente vai chegar a uma compreensão satisfatória porque os olhos se apóiam no significado daquilo que vêem. Se o leitor não conseguir encontrar significação na linguagem, não vai conseguir fazer uma boa leitura, vai apenas decodificar os símbolos escritos, mas não vai chegar a uma compreensão efetiva e o ato de ler se perde em sua essência.

Infelizmente, é a leitura de decodificação que tem predominado entre a maioria dos estudantes e na prática pedagógica dos professores. Esse fato pode ser facilmente observado quando não conseguem alcançar o significado de simples comandos de atividades corriqueiras de sala de aula, o que tem reflexo também nas produções de suas respostas a questões analítico-discursivas, já que o ato de escrever está sendo reduzido apenas às atividades de cópia, inclusive nos trabalhos de pesquisa. Isso tem gerado uma verificação de um nível de aprendizagem insatisfatório.

Essa é uma realidade que deve ser combatida urgentemente, em favor de uma educação de qualidade, que leve realmente o educando a construir conhecimentos críticos 
sobre a realidade apresentada, e não só absorver informações dadas como verdades absolutas e não passíveis de contestação.

Outro aspecto que faz toda a diferença está na motivação dos alunos, pois sem isto não há motivação; sem motivação, não há querer ler, querer aprender, querer absorver novos conhecimentos.

Para tanto, é necessário que se desenvolva uma compreensão primeira sobre o próprio ato de ler, envolvendo os vários tipos de leitura que se pode fazer e os objetivos de cada um deles.

Os alunos da EJA - Ensino de Jovens e Adultos precisam se conscientizar que ler é estimulante. Tal como as pessoas, os livros podem ser intrigantes, melancólicos, assustadores, e por vezes, complicados. Os livros partilham sentimentos e pensamentos, feitios e interesses. Os livros colocam-nos em outros tempos, outros lugares, outras culturas. Os livros ajudam-nos a sonhar, fazem-nos pensar.

Qualquer que seja o objetivo de uma leitura, ele sempre vai envolver estratégias de ensino- aprendizagem, mas é importante levar em consideração que ninguém vai ler algo com atenção se não vê uma utilidade nessa leitura, pois lemos e escrevemos sempre para atender a uma necessidade pessoal.

Então, para este projeto, a tarefa principal é promover essa motivação para a leitura e escrita nos estudantes, pois, acredita-se que somente através do interesse do próprio leitor é que se pode alcançar um bom nível de compreensão textual que se reflita em proficiência na escrita, já que "o sentido de um texto é construído na interação textos-sujeitos e não algo que preexista a essa interação". (KOCH \& ELIAS, 2006:11)

De acordo com Ezequiel Theodoro da Silva (1996) escrever e ler são atos complementares: um não pode existir sem o outro. $O$ ato de ler envolve uma direção na consciência para a expressão referencial escrita, capaz de gerar pensamento e doação de significado. Então, afirma Ezequiel que a leitura (ou resultado do ato de se atribuir um significado ao discurso escrito) passa a ser uma via de acesso a participação do homem nas sociedades letradas, na medida em que permite a entrada e a participação no mundo da escrita; a experiência dos produtos culturais que fazem parte desse mundo só é possível pela existência de leitores. Daí ser a escola uma instituição formal que objetiva a aprendizagem não só de falar, mas como principalmente de escrever e ler.

Com a realização deste projeto esperamos despertar nos nossos alunos o interesse pela leitura, o prazer em ler. A semente será lançada e é só adubá-la e regá-la para colhermos bons frutos, bons leitores.

\section{5 - OBJETIVOS}




\section{1- Objetivo Geral}

- Contribuir para formação de leitores críticos, criativos, curiosos e inventivos na Educação de Jovens e Adultos do Centro de Ensino Fundamental 2 do Riacho Fundo I.

\subsection{Objetivos Específicos}

- Adquirir conhecimentos novos através da leitura;

- Estimular a criatividade, o espírito inventivo e a curiosidade dos estudantes com a intenção de contribuir para formar uma nova geração de leitores, mais crítica;

- Envolver a comunidade escolar em atividades interdisciplinares que envolvam a leitura, escrita e interpretação.

\section{6 - ATIVIDADES / RESPONSABILIDADES}

- Promover o hábito da leitura e proporcionar competências para a escrita através de produção textual;

- Momento de leitura na biblioteca e sala de leitura;

- Debate sobre os textos lidos;

- Anotações e exercícios;

- Escolhas de autores brasileiros para serem trabalhados durante o ano com pesquisa de biografias, gêneros literários, etc.

- Aumentar o nível de conscientização sobre o ato de ler.

Para os alunos do EJA - Ensino de Jovens e Adultos, $2^{\circ}$. Segmento primeiramente será fixada uma aula semanal direcionada ao projeto, os professores das respectivas turmas acompanharão os alunos até a biblioteca, onde serão selecionados pela professora da turma e pela bibliotecária, livros de vários autores. Os alunos lerão o livro escolhido por eles, responderão um questionário e depois farão um resumo. Após a conclusão do trabalho pelos alunos, todos se reunirão na biblioteca onde será debatido o assunto sobre a importância da leitura. Os alunos que conseguirem concluir o trabalho primeiro continuarão freqüentando a biblioteca e lerão outros livros de livre escolha por eles. Encerraremos este trabalho com a presença dos alunos que farão depoimentos sobre este projeto, da direção, coordenação, professores e um lanche trazidos pelos próprios alunos.

\section{7 - RESULTADOS ESPERADOS}


Resgatar o hábito da leitura e da escrita, contribuindo para a formação do cidadãoleitor-escritor, ampliar seus conhecimentos, desenvolver o prazer em ler.

Participação e um bom desempenho no que diz respeito à compreensão da mensagem escrita, para tentar transmitir a essência desta mensagem aos colegas. $O$ planejamento de leitura será fundamental para a escola e a implementação de qualquer ação; aqui, a educação estará realmente voltada para a transformação qualificando o universo cultural dos jovens e adultos da EJA.

\section{8 - CRONOGRAMA}

\begin{tabular}{|c|c|c|}
\hline Objetivos Específicos & Ações/Atividades & Cronograma \\
\hline \multirow{5}{*}{$\begin{array}{c}\text { Estimular a criatividade, o espírito } \\
\text { inventivo e a curiosidade com a } \\
\text { intenção de contribuir }\end{array}$} & $\begin{array}{l}\text { Uma discussão prévia sobre a } \\
\text { questão da leitura }\end{array}$ & \multirow{5}{*}{$\begin{array}{c}\text { Agosto a } \\
\text { Dezembro/2010 }\end{array}$} \\
\hline & $\begin{array}{l}\text { Momento de leitura na biblioteca } \\
\text { para formar uma geração de } \\
\text { leitores, mais crítica }\end{array}$ & \\
\hline & $\begin{array}{l}\text { Promover o hábito da leitura e } \\
\text { proporcionar competências para a } \\
\text { escrita através de produção textual }\end{array}$ & \\
\hline & Debate sobre os textos lidos & \\
\hline & $\begin{array}{l}\text { Pesquisa de biografias de autores } \\
\text { Brasileiros }\end{array}$ & \\
\hline \multirow{2}{*}{$\begin{array}{c}\text { Envolver a comunidade escolar } \\
\text { em atividades }\end{array}$} & $\begin{array}{l}\text { Levar a proposta à coordenação } \\
\text { interdisciplinares que envolvam a } \\
\text { leitura, a escrita e interpretação }\end{array}$ & \multirow{2}{*}{ Agosto/2010 } \\
\hline & $\begin{array}{l}\text { Proposição de } \text { atividades } \\
\text { interdisciplinares pelo coletivo da } \\
\text { escola }\end{array}$ & \\
\hline
\end{tabular}

\section{9 - PARCEIROS}

- Coordenadores, Direção, Comunidade, CCBB, Cinemark

- Professoras;

- Bibliotecárias;

- Alunos do $2^{\circ}$. Segmento modalidade da EJA - Ensino de Jovens e Adultos 


\section{0 - ORÇAMENTO}

Não existe gasto financeiro para a realização deste projeto.

\section{1 - ACOMPANHAMENTO E AVALIAÇÃO}

As avaliações serão realizadas ao longo da execução do projeto que será levado em consideração a participação e envolvimento dos alunos nas atividades e a interação entre os alunos do grupo. Devemos lembrar que para o desenvolvimento do projeto, as atividades de incentivo deverão ser constantes, e vale a pena ressaltar que não é só por parte dos professores de língua portuguesa, mas também dos professores das demais disciplinas. 


\section{REFERÊNCIAS}

- ÁVILA, Adriana Aparecida. Citações em Documentos de acordo com a Norma ABNT1052/2002. Porto Alegre, 2006.

- Blog do Citador - http://citador.weblog.com.pt

- EducaRede/www.educarede.org.br

- FREIRE, Paulo. A importância do ato de ler. São Paulo: Cortez, 1987.

- Incentivo à Leitura/www. pesquisa.uncnet.br

- Jornal Correio Braziliense

- KATO, Mary Aizawa. O aprendizado da leitura.

- KOCH \& Elias, 2006:11)

- Projeto Leitura e Escrita-www.scribd.com

- SILVA, Ezequiel Theodoro da. O ato de ler. 7 ed. São Paulo: Cortez, 1996F Leitura \& Realidade Brasileira. Porto Alegre: Mercado Aberto, 1983.

- WWW.google.com.br 